\title{
Major ethnic group differences in breast cancer screening uptake in Scotland are not extinguished by adjustment for indices of geographical residence, area deprivation, long-term illness and education
}

\section{N Bansal*,', RS Bhopal', MFC Steiner' and DH Brewster ${ }^{1,2}$ on behalf of the Scottish Health and Ethnicity Linkage Study}

'Edinburgh Ethnicity Health Research Group, Centre for Population Health Sciences, University of Edinburgh, Teviot Place, Edinburgh EH8 9AG, UK;

${ }^{2}$ Information Services Division, NHS National Services Scotland, Gyle Square, I South Gyle Crescent, Edinburgh EHI 2 9EB, UK

\begin{abstract}
BACKGROUND: Breast cancer screening data generally show lower uptake in minority ethnic groups. We investigated whether such variations occur in Scotland.

METHODS: Using non-disclosive computerised linkage we combined Scottish breast screening and Census 200 I data. Non-attendance at first breast-screening invitation (2002-2008) was compared between I I ethnic groups using age-adjusted risk ratios (RR) with 95\% confidence intervals (Cl), multiplied by 100, using Poisson regression.

RESULTS: Compared with the White Scottish $(R R=100)$, non-attendance was similar for Other White British (99.5, 95\% Cl 96.I - 103.2) and Chinese (I I2.8, 95\% Cl 96.3- | 32.2) and higher for Pakistani (I81.7, 95\% Cl I64.9-200.2), African (I 62.2, 95\%

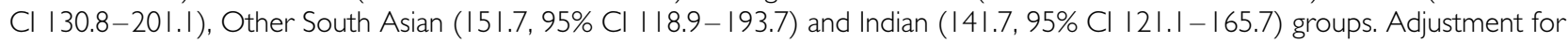
rural vs urban residence, long-term illness, area deprivation and education, associated with risk of non-attendance, increased the RR for non-attendance except for Pakistani women where it was modestly attenuated $(R R=|64.9$,$| | 49.4-\mid 82.1)$.

CONCLUSION: Our data show important inequality in breast cancer screening uptake, not attenuated by potential confounding factors. Ethnic inequalities in breast screening attendance are of concern especially given evidence that the traditionally lower breast cancer rates in South Asian groups are converging towards the risks in the White UK population. Notwithstanding the forthcoming review of breast cancer screening, these data call for urgent action.
\end{abstract}

British Journal of Cancer (2012) 106, I36 I-1366. doi:I0.1038/bjc.2012.83 www.bjcancer.com

Published online 13 March 2012

(c) 2012 Cancer Research UK

Keywords: breast cancer; cancer screening; ethnicity; inequalities

Migrant studies have demonstrated marked variation in cancer mortality by country of birth in Europe, with, for example, higher risks in Scottish-born and Irish-born and lower risk in South Asiaborn migrants in England (Wild et al, 2006). Country of birth data together with limited studies on ethnicity assessed directly (Winter et al, 1999; Smith et al, 2003; Jack et al, 2007, 2009; Ali et al, 2010; Day et al, 2010), and on ethnic minority populations born in the country (Cummins et al, 2001; McKinney et al, 2003), show that such variations are mediated by environmental factors (Harding and Rosato, 1999). Changing risk with duration of residence (Harding, 2003) and convergence of risk factors, together with poorer declines in traditionally low-risk groups (Harding et al, 2009; Arnold et al, 2010; Mangtani et al, 2010), threaten the healthy migrant advantage (Zaman and Mangtani, 2007). Breast cancer is one of the most common cancers in women of all ethnic groups (Bhopal and Rankin, 1996) in the United

*Correspondence: Dr N Bansal; E-mail: n.bansal@ed.ac.uk Received 28 November 2011; revised 16 February 2012; accepted 20 February 2012; published online 13 March 2012
Kingdom, United States and probably globally (Kamangar et al, 2006). Emerging evidence shows that rates of breast cancer in traditionally low-risk groups such as South Asian women are converging towards the majority White population in the United Kingdom (Winter et al, 1999; Jack et al, 2009; Ali et al, 2010) and the United States (Blesch et al, 1999).

Inequalities in health service use and treatment can augment ethnic differences in disease outcomes. For many years, there has been controversy about the balance of harms (such as over-diagnosis and over-treatment) and benefits of breast cancer screening (Bewley, 2011), leading to the recent establishment of an independent review in the United Kingdom (Richards, 2011). However, it is widely accepted that breast cancer screening can reduce the risk of disease-specific mortality through early detection and treatment, and pending the results of the review, women in the UK have been advised to continue to take up invitations for screening. In Scotland, since 1988 the United Kingdom National Health Service Breast Screening Programme (NHSBSP) has invited women aged 50 (to 64 until 2003-2004 and then to 70 years thereafter) for screening once every 3 years. However, the associated data set does 
not include ethnicity to allow assessment of inequalities in service use.

Data from England and the US suggest ethnic inequalities in cancer health service use. For example, studies have shown relatively advanced breast cancer stage of disease at diagnosis in Indian, Pakistani and Black women in the United Kingdom and United States (Li et al, 2003; Morris et al, 2007; Jack et al, 2009); diagnostic delay in Black and South Asians (Neal and Allgar, 2005); and ethnic inequalities in treatment (Jack et al, 2009) with poorer survival in Black African women in the UK (Jack et al, 2009). There is less information on screening uptake and inequalities in cancer service use in other minority ethnic groups such as the Chinese and Mixed Background groups and in non-majority White groups, which are particularly important given the heterogeneity in cancer risk noted in United Kingdom White groups (Harding et al, 2009). The non-White population is smaller in Scotland than in England, at the 2001 census constituting $2 \%$ of the total population (clustered mostly in Glasgow and Edinburgh) compared with England where it is $8 \%$. Pakistanis form the majority $(31.3 \%)$ of the non-White population, followed by Chinese (16\%), Indians (14.8\%), Mixed Background (12.6\%) with Caribbean (1.8\%) and Black Scottish (1.1\%) forming the smallest groups. This is in contrast to England where Indians form the largest ethnic minority group and Chinese the smallest (General Register Office for Scotland, 2001).

The presence and extent of ethnic inequalities, and their relation to socio-economic factors, in Scotland are unknown. This information gap is contrary to the legal and policy commitments in Scotland, to improve the health of minority ethnic groups (Scottish Executive Health Department, 2002), reduce health inequalities (Scottish Executive, 1999) and promote racial equality (Home Office, 2001). These mandates were profoundly undermined by the lack of a sound evidence base to underpin policy development, service planning, delivery of health services and research (Netto et al, 2001).

To fill the information gap, the Scottish Health and Ethnicity Linkage Study was established (Bhopal et al, 2011). We investigated ethnic variations in breast screening uptake and tried to understand these in relation to socio-economic area deprivation, education, geography and health status.

\section{METHODS}

\section{Breast cancer screening data}

Women invited for screening are selected and identified using the Community Health Index (CHI), which is linked to the Scottish Breast Screening Programme (SBSP) Information System. The SBSP Information System extracts details of eligible women for screening and these details are sent to the relevant GPs for checking; any discrepancies/amendments are then fed back and the system is updated. The SBSP Information System provides the SBSP with the functionality to invite eligible women via a call and recall facility, to allocate appointments and record the results of screening episodes. Once a woman has been selected for screening, a record is created for that individual and held on the SBSP Information System. Information relating to each step as a woman moves through her screening episode (including attendance) is collected on paper forms and saved on to the SBSP Information System. These data are collected for each individual for each individual episode. Patients only receive a reminder letter if they 'Do Not Attend' their appointment (regardless of their appointment type). Those due to attend the static centre are sent a reminder 4 weeks after their date of appointment and those due to attend a mobile unit are sent a reminder 2 weeks after their date of appointment. Information entered into the SBSP system is validated at the point of entry, which ensures data are accurate and of a high standard.

\section{Community Health Index to census linkage}

As described previously (Fischbacher et al, 2007) (Bhopal et al, 2011), an anonymised data set containing census (respondent defined ethnicity and sociodemographic variables from the 2001 census) and various health outcomes, including breast screening uptake, was created using the probability linkage method, linking the census 2001 for Scotland to the Scottish CHI (register of patients using the NHS). Approximately $95 \%$ of the population enumerated in the 2001 census was linked to the CHI overall (4.65 million, with $85 \%$ or more linked in every ethnic group). Taking into account the census enumeration rate $(96 \%)$, this represents about $91 \%$ of the population resident in Scotland in April 2001 (Bhopal et al, 2011).

\section{Data analysis}

As shown in Figure 1, we identified a cohort of women born between 1952 and 1956 and expected to have received a first routine breast screening invitation between 2002 and 2008 (allowing for the 3-year time period ( $50-53$ years of age) over which a women can expect to receive first invitation). We limited the cohort to normal routine invitations only and excluded women being recalled early or under review for clinical reasons. Eighty-nine percent of breast screening records were linked to the census. We compared breast screening uptake by ethnic group. We identified potential confounders relating to socio-economic area deprivation (Scottish Index of Multiple Deprivation (SIMD) quintiles), education (here defined as having any recognised qualification $v s$ none), geography (defined here as rural, small towns, and urban) and health status (long-term illness, yes/no) from the census data set and explored the association between these factors, breast screening uptake, and ethnic group.

Breast screening uptake (non-attendance) was compared between ethnic groups and data are presented here as age-adjusted risk ratios (RR) for non-attendance, with $95 \%$ confidence intervals around summary measures using Poisson's regression with robust variance. The standard comparison population was the White Scottish population at the 2001 census. Data were analysed using SAS version 9 (SAS Institute Inc., Cary, NC, USA).

Owing to small numbers, the following ethnic groups - African, Caribbean and Black Scottish or Other Black - have been

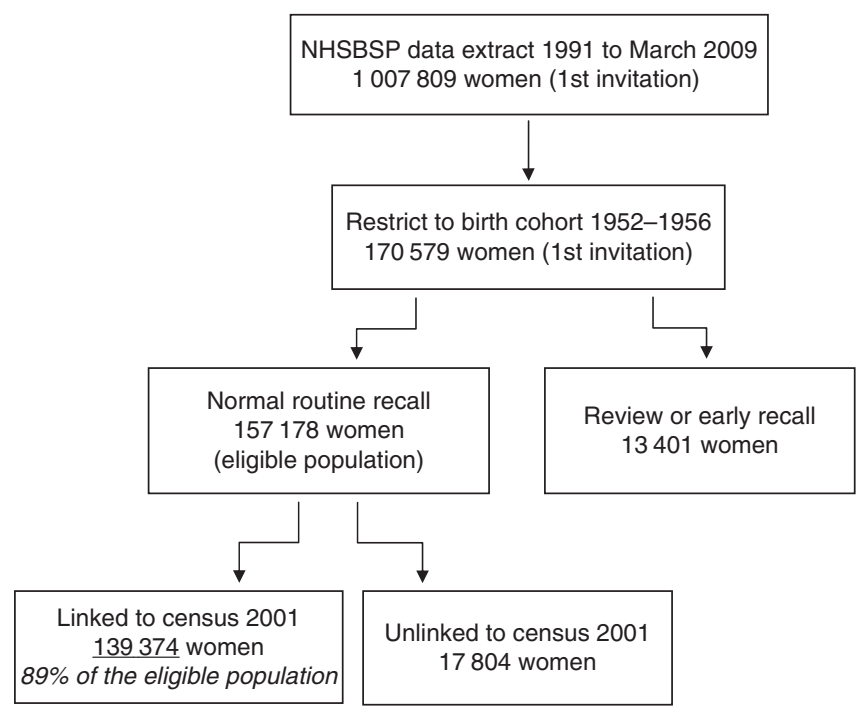

Figure I Selection of cohort. 
amalgamated and are here referred to as the 'African' group; the 'Other South Asians' includes the Bangladeshi group.

In the results we focus on findings where the $95 \%$ CI does not include 100, the value for the standard White Scottish comparison population.

\section{Ethics and disclosure control}

The analysis was conducted on a standalone computer in a locked room in the General Register Office for Scotland (Now National Records of Scotland) by named researchers (NB, MS) following a strict protocol to prevent inadvertent disclosure.

The work was approved by the Multicentre Research Ethics Committee (for Scotland) and the Privacy Advisory Committee of NHS National Services Scotland. The ethical and other permissions and related issues have been reported in detail, including an independent assessment by an ethicist (Boyd, 2007).

\section{RESULTS}

\section{Breast screening non-attendance}

In all, 139374 records were identified as being first routine invites between 2002 and 2008 from the NHSBSP data. Overall, 23\% of the invited cohort did not attend (DNA), with clear ethnic variations (Table 1). Differences that are statistically robust are considered below. Table 2 shows that compared with the White Scottish (100), age-adjusted RR for non-attendance were higher for every ethnic

Table I Number of women invited and percentage that did not attend (DNA) after first invitation for breast screening by ethnic group in Scotland (2002-2008)

\begin{tabular}{lrrc}
\hline Ethnic group & $\begin{array}{c}\text { DNA } \\
(\boldsymbol{n})\end{array}$ & $\begin{array}{c}\text { Invited } \\
(\mathbf{n})\end{array}$ & $\begin{array}{c}\text { DNA } \\
\text { (\%) }\end{array}$ \\
\hline White Scottish & 28398 & 123026 & 23.1 \\
Other White British & 2541 & 11056 & 23 \\
White Irish & 368 & 1411 & 26.1 \\
Other White & 542 & 1874 & 28.9 \\
Indian & 106 & 324 & 32.7 \\
Pakistani & 241 & 575 & 41.9 \\
Other South Asian & 42 & 120 & 35 \\
Chinese & 114 & 438 & 26 \\
African & 52 & 139 & 37.4 \\
Any Mixed Background & 48 & 150 & 32 \\
Other Ethnic Group & 71 & 261 & 27.2 \\
Total & 32523 & 139374 & 23.3 \\
\hline
\end{tabular}

group except the Other White British, Chinese and Other Ethnic groups, where they were similar. Risks of non-attendance were highest for Pakistani (181.7) followed by African (162.2), Other South Asian (151.7), Indian (141.7), Any Mixed Background (138.4) and Other White (125.3) women.

\section{Other factors associated with breast screening uptake}

Besides ethnicity, living in a rural vs urban area, having a longterm illness, area deprivation and individual educational status were factors associated with risk of non-attendance. Table 2 shows the effect of additional adjustment for each of these variables. Further adjustment for SIMD increased the RR in all ethnic groups relative to the White Scottish, incurring the largest change in most ethnic groups compared with other indicators. Age- and SIMDadjusted ratios were now also higher for the Other White British, Chinese and Other Ethnic groups compared with the White Scottish. Adjustment for education increased RR in the White groups and decreased the RR in Pakistani, Indian and Chinese women. For Pakistani women, adjustment for education had the greatest attenuating effect reducing excess risk by $20 \%$. Further adjustment for long-term illness and for urban/rural status incurred smaller changes compared with SIMD and education. Adjustment for all these factors, as shown in Figure 2, increased the RR in all non-Scottish groups except for Pakistani women where it was attenuated $(164.9,149.4$ to 182.1$)$.

\section{DISCUSSION}

\section{Principal findings}

These first-ever Scottish data demonstrate that 23 years after the introduction of the United Kingdom national breast screening programme, ethnic inequalities in uptake at first invite are substantial for almost every non-white group in Scotland. These data are of concern especially given that women who attend breast screening at first invitation are more likely to attend for subsequent screens (Price et al, 2010). There are no published comparative ethnicity data to show how poor screening uptake is reflected in stage of disease at diagnosis in Scotland. However, drawing from English data, inequalities are likely to be considerable, and ethnic inequity in the extent of preventable cancer mortality may be marked, especially for Pakistani and African women.

\section{Findings in relation to the literature}

Ethnic variations in use of cancer screening services are seen internationally (Kagawa-Singer and Pourat, 2000; Kandula et al, 2006;

Table 2 Risk ratios for non-attendance adjusted by age, deprivation, education, long-term illness and urban/rural status with $95 \% \mathrm{Cl}$ by ethnic group

\begin{tabular}{|c|c|c|c|c|c|}
\hline Ethnic group & Age & $\begin{array}{l}\text { Age and } \\
\text { SIMD }^{a}\end{array}$ & $\begin{array}{l}\text { Age and } \\
\text { education }\end{array}$ & $\begin{array}{c}\text { Age and long-term } \\
\text { illness }\end{array}$ & $\begin{array}{c}\text { Age and urban/rural } \\
\text { residence }^{d}\end{array}$ \\
\hline White Scottish & 100 & 100 & 100 & 100 & 100 \\
\hline Other White British & $99.5(96.1,103.2)$ & | 0.9 (|07.|, | | 5.0) & I07.0 (I03.2, | | 0.9) & $101.3(97.8,105.0)$ & 104.8 (101.1, 108.7) \\
\hline White Irish & | | $2.9(\mid 03.3,123.3)$ & | $8.4(\mid 08.4,129.4)$ & | $18.9(108.8,129.9)$ & | $13.6(104.0,124.1)$ & | $12.3(102.8,122.7)$ \\
\hline Other White & $125.3(|| 6.6, \mid 34.6)$ & | $38.8(|29.2| 49.2)$, & | $35.2(|25.8| 45.3)$, & $127.3(|| 8.5, \mid 36.7)$ & $127.3(|| 8.5, \mid 36.8)$ \\
\hline Indian & $141.7(121.1,165.7)$ & $158.8(\mid 35.8,185.6)$ & | $37.7(\mid 17.6,161.1)$ & 139.7 (| |9.1, |63.8) & $137.7(\mid 17.7,161.1)$ \\
\hline Pakistani & $181.7(164.9,200.2)$ & I83.4 (166.3, 202.3) & $162.3(\mid 47.3,178.9)$ & $167.7(151.9,185.1)$ & $173.4(157.4,191.1)$ \\
\hline Other South Asian & | 51.7 (| | 8.9, |93.7) & $160.5(125.5,205.2)$ & $156.0(121.9,199.5)$ & |48.6 (| |6.5, | 89.4) & |47.8 (| | 5.8, | 88.7) \\
\hline Chinese & | | $2.8(96.3, \mid$ | 32.2) & |23.| (|05.0, |44.3) & |03.| (87.9, | 20.9) & | |6.| (99.1, |35.9) & $109.6(93.6,128.5)$ \\
\hline African & $162.2(\mid 30.8,201.1)$ & $163.9(131.8,203.8)$ & $174.0(\mid 40.2,216.0)$ & $162.0(\mid 30.8,200.7)$ & | $58.7(\mid 28.2,196.5)$ \\
\hline Any Mixed Background & | $38.4(|09.5| 74.9)$, & |42.7 (| | 2.9, | 80.4) & |44.| (| |4.0, | 82.2) & $136.7(107.9,173.1)$ & | $38.8(|09.6| 75.7)$, \\
\hline Other Ethnic Group & | $17.8(96.6, \mid 43.6)$ & $128.8(\mid 05.6,157.1)$ & | $19.0(97.6,145.2)$ & | $21.7(99.7, \mid 48.5)$ & | $17.6(96.3,143.6)$ \\
\hline
\end{tabular}

${ }^{\mathrm{a} S}$ Scottish Index of Multiple Deprivation (SIMD) quintiles. ${ }^{\mathrm{b}}$ Qualification vs none. ${ }^{\mathrm{c} D e f i n e d ~ a s ~ y e s / n o . ~}{ }^{\mathrm{d}}$ Defined as rural, small towns, urban. 


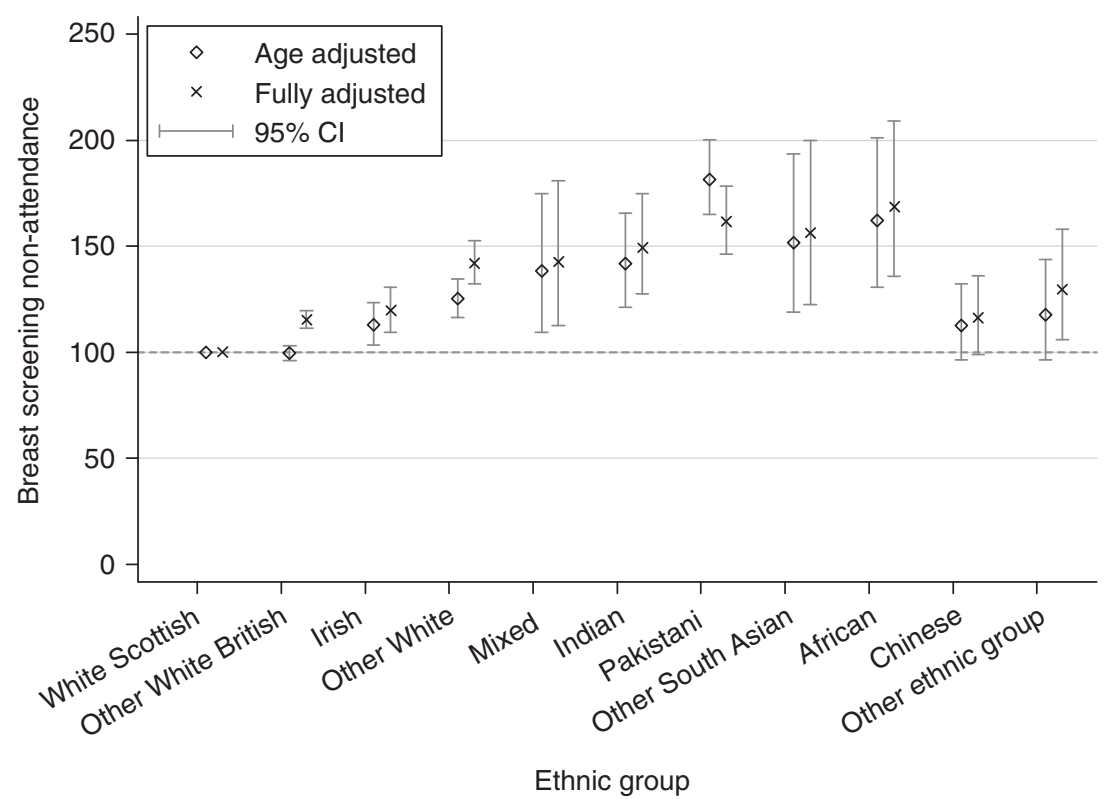

Figure 2 Non-attendance age- and fully-adjusted (age, education, deprivation, long-term illness and urban/rural status) RR with $95 \%$ confidence intervals by ethnic group.

Ho and Dinh, 2011). Lower cancer screening uptake has been noted in migrant (Webb et al, 2004) and ethnic minority women in England with lower uptake of breast screening in South Asian (Szczepura et al, 2008; Price et al, 2010) and Black (Renshaw et al, 2010) women. Despite limitations of studies using other indicators as a proxy for ethnicity such as name identification (Cummins et al, 1999; Nanchahal et al, 2001) and area-based methods, these English data are compatible with our findings showing lower breast cancer screening in South Asian and African women. Our data show clear heterogeneity among South Asian women, with worse uptake for Pakistani women, followed by Other South Asian (mostly Bangladeshi) and with Indian women doing better than South Asian counterparts. This is consistent with previous data from England showing particularly low rates for Muslim South Asian women (Szczepura et al, 2008; Price et al, 2010). Surprisingly, we found that Chinese women had more similar uptake to White Scottish women, and not the poor utilisation characteristic of ethnic minority women and as seen in American Chinese women ( $\mathrm{Tu}$ et al, 1999). Our study also demonstrated differences between White groups, with poorer uptake in Irish and Other White women but not in Other White British compared with the White Scottish. We found no other data exploring breast screening uptake in United Kingdom White groups.

Understanding variation between the White groups, and between ethnic minority women, particularly between the somewhat heterogeneous South Asian group and the Chinese, is potentially a key to understanding variation in service use.

Although socio-economic factors such as socio-economic deprivation (Power et al, 2009; Steele et al, 2010) and wealth (Moser et al, 2009) are important for service use, their role in explaining ethnic variations in breast screening uptake in the UK have not been fully studied. In our study, despite ethnic differences in area deprivation, education, long-term illness and urban/rural residence, these factors did little to attenuate ethnic differences in uptake between White Scottish and other White groups and between ethnic minority groups.

Studies exploring ethnic variations in breast screening uptake in the United Kingdom and United States suggest a strong role for cultural factors. Most of the data from England focus on South Asian women with data on Black and Chinese women originating mainly from the US. These data suggest that barriers to uptake include lack of knowledge and awareness of breast cancer and breast screening, and differences in perceived risk (Naish et al, 1994; Kernohan, 1996; Sadler et al, 2001, 2007; Watts et al, 2004; Jacobs et al, 2005; Thomas et al, 2005; Abdullahi et al, 2009; Robb et al, 2010). These, and other factors such as modesty, fear, embarrassment relating to breast examination particularly by male staff, differing attitudes, perceptions and beliefs of health and health service, language difficulties - both English proficiency and literacy in own language (Naish et al, 1994; Kernohan, 1996; Sadler et al, 2000; Jacobs et al, 2005; Thomas et al, 2005; Lee-Lin et al, 2007; Abdullahi et al, 2009; Banning, 2011), have been highlighted as explanatory factors for ethnic variations in uptake. For South Asian women in particular, low priority for self-care due to extended family responsibilities has been identified as an additional limiting factor (George and Ramkissoon, 1998).

Szczepura (2005) categorised these identified explanations for poor health care access into (1) 'personal (intrinsic)' factors (cultural differences, language and literacy and user ignorance) relating to the specific and particular needs of ethnic minority populations and (2) 'organisational (extrinsic)' factors (differential needs and provision, location of services and staff training needs). Both need to be considered when planning services for multiethnic and multicultural populations with the awareness that these needs may change (Szczepura, 2005) with level of acculturation, age and generational status of these communities.

There is a dearth of evidence for effective interventions to improve access in ethnic minority populations (Sokal, 2010). Given the complexity of cultural factors affecting uptake, evaluations of carefully tailored interventions are needed. A study in Canada showed the effectiveness of a culturally tailored and languagespecific, written health education for South Asian women resulting in increased uptake of clinical breast examination (Ahmad et al, 2005). In London, a multi-pronged approach using targeted outreach work via community organisations and GP incentives to increase uptake, text message reminders and improved breast screening services, including a dedicated call-centre staff training, and interpreters, were seen to be important modifications in improving uptake (Eilbert et al, 2009).

Our data are of special concern given data showing advanced cancer stage at diagnosis in ethnic minority women (Cuthbertson 
et al, 2009), and are particularly worrying for South Asian women who are reported to present later for breast cancer and with larger primary tumours (Velikova et al, 2004). Data in Scotland on disease stage at presentation need to be examined by ethnic group.

\section{Strengths and limitations of the study}

The strength of the study is the overall size, its population base, the availability of an ethnic code completed by the householder on behalf of the household, information on a wide range of ethnic groups studied simultaneously, information on relevant potential confounding factors, and being the first presentation of Scottish data by ethnic group. Recording of ethnicity data in the 2001 census is fairly complete (96\%). The weaknesses of the study include the small population size for some non-White populations (African, Other South Asians, Any Mixed Background) requiring aggregation of heterogeneous groups such as African and Caribbean; and that $11 \%$ of breast screening records did not have a corresponding census file and we were therefore unable to explore the unlinked population. As our cohort is restricted to women attending breast screening in 2002 and beyond, it is possible that many of these $(11 \%)$ were not resident in Scotland during the 2001 census. We do not have information on nonlinking records and reasons for non-links may relate partly to failure to find (i.e., participant not registered with a GP or no contact with the NHS in Scotland) or match (misspelling or missing information on names or other identifiers used for matching) records.

\section{CONCLUSION}

Our data showing substantial ethnic inequalities in breast screening attendance are of concern, especially given evidence suggesting that the traditionally lower breast cancer rates in South Asian groups are converging with higher risk White populations in the United Kingdom (Harding et al, 2009). Our data extend and corroborate data from England showing poorer uptake in all South Asian women, but with clear heterogeneity, not explained here by socioeconomic factors. Notwithstanding the forthcoming review of breast cancer screening (Bewley, 2011; Richards, 2011), these data call for urgent action. More work is needed to understand and address the low service use in these ethnic minority groups with particular urgency for Pakistani and African women. Meanwhile, policymakers and health-care staff need to respond to the existing evidence base highlighting multiple barriers affecting screening uptake in ethnic minority groups and ensure that services and staff are culturally sensitive and competent.

\section{ACKNOWLEDGEMENTS}

We thank the Chief Scientist's Office for funding this study (grant (CZH/4/432), and NHS Health Scotland for a supplementary grant. The Equality and Diversity Information Programme of the Information Services Division (ISD) of NHS National Services Scotland. ISD and the General Register Office for Scotland both made 'in-house' contributions to the work. Joan Jamieson (ISD) was a co-investigator and general adviser. We thank Donna Mikolajczak, senior information analyst at National Services Scotland, for her support and advice. Referees critical feedback helped improve an earlier draft. The researchers acted independently of the funding body and the study sponsor (the University of Edinburgh) at all stages of the work.

\section{Conflict of interest}

The authors declare no conflict of interest.

\section{Author contributions}

Bansal was the lead writer, research fellow, data analyst and co-ordinator of the study, Bhopal was the PI and Brewster was Chair of the cancer sub-group of SHELS, Steiner was the study analyst. All authors helped plan the study, evolve analysis plans, interpret data and critically revise successive drafts of the manuscript.

\section{Other contributors from the Scottish Health and Ethnicity Linkage Study investigators}

Chris Povey had the idea of linking the census data to the data held by ISD and he performed most of the linkage work, including developing methods. Jim Chalmers had the original idea for the use of one-way encryption. Ganka Mueller was key in linking census data to health data. Colin Fischbacher chaired the Steering Committee of the project and was co-PI. Kirsty MacLachlan advised throughout. These contributors did not meet the ICMJE or our own publication criteria for co-authorship. The authorship and note of contributions has been agreed by all the investigators named. Bhopal is the guarantor.

\section{REFERENCES}

Abdullahi A, Copping J, Kessel A, Luck M, Bonell C (2009) Cervical screening: Perceptions and barriers to uptake among Somali women in Camden. Public Health 123(10): 680-685

Ahmad F, Cameron JI, Stewart DE (2005) A tailored intervention to promote breast cancer screening among South Asian immigrant women. Soc Sci Med 60(3): 575-586

Ali R, Barnes I, Kan SW, Beral V (2010) Cancer incidence in British Indians and British whites in Leicester, 2001-2006. Br J Cancer 103(1): 143-148

Arnold M, Razum O, Coebergh JW (2010) Cancer risk diversity in non-western migrants to Europe: an overview of the literature. Eur J Cancer 46(14): 2647-2659

Banning M (2011) Black women and breast health: a review of the literature. Eur J Oncol Nurs 15(1): 16-22

Bewley S (2011) The NHS breast screening programme needs independent review. BMJ 343: d6894

Bhopal R, Fischbacher C, Povey C, Chalmers J, Mueller G, Steiner M, Brown H, Brewster DH, Bansal N (2011) Cohort profile: Scottish Health and Ethnicity Linkage Study of 4.65 million people exploring ethnic variations in disease in Scotland. Int J Epidemiol 40(5): 1168-1175
Bhopal RS, Rankin J (1996) Cancer in minority ethnic populations: priorities from epidemiological data. Br J Cancer Suppl 29: S22-S32

Blesch KS, Davis F, Kamath SK (1999) A comparison of breast and colon cancer incidence rates among native Asian Indians, US immigrant Asian Indians, and whites. J Am Diet Assoc 99(10): 1275-1277

Boyd KM (2007) Ethnicity and the ethics of data linkage. BMC Public Health 7: 318

Cummins C, Winter H, Cheng KK, Maric R, Silcocks P, Varghese C (1999) An assessment of the Nam Pehchan computer program for the identification of names of south Asian ethnic origin. J Public Health Med 21(4): 401 - 406 Cummins C, Winter H, Maric R, Cheng KK, Silcocks P, Varghese C, Batlle G (2001) Childhood cancer in the south Asian population of England (1990-1992). Br J Cancer 84(9): 1215-1218

Cuthbertson SA, Goyder EC, Poole J (2009) Inequalities in breast cancer stage at diagnosis in the Trent region, and implications for the NHS Breast Screening Programme. J Public Health (Oxf) 31(3): 398-405

Day M, Poole J, Bennett JA, Peake MD (2010) Changes in lung cancer incidence in South Asians in Leicester, 1990-2005. J Public Health (Oxf) 32(2): $230-235$ 
Eilbert KW, Carroll K, Peach J, Khatoon S, Basnett I, McCulloch N (2009) Approaches to improving breast screening uptake: evidence and experience from Tower Hamlets. Br J Cancer 101(Suppl 2): S64-S67

Fischbacher CM, Bhopal R, Povey C, Steiner M, Chalmers J, Mueller G, Jamieson J, Knowles D (2007) Record linked retrospective cohort study of 4.6 million people exploring ethnic variations in disease: myocardial infarction in South Asians. BMC Public Health 7: 142

General Register Office for Scotland (2001) Scotland Census 200110 February 2012

George U, Ramkissoon S (1998) Race, gender, and class: interlocking oppressions in the lives of South Asian women in Canada. Affilia: $J$ Women Soc Work 13(1): $102-119$

Harding S (2003) Mortality of migrants from the Indian subcontinent to England and Wales: effect of duration of residence. Epidemiology 14(3): 287-292

Harding S, Rosato M (1999) Cancer incidence among first generation Scottish, Irish, West Indian and South Asian migrants living in England and Wales. Ethn Health 4(1-2): 83-92

Harding S, Rosato M, Teyhan A (2009) Trends in cancer mortality among migrants in England and Wales, 1979-2003. Eur J Cancer 45(12): 2168 - 2179

Ho IK, Dinh KT (2011) Cervical cancer screening among Southeast Asian American women. J Immigr Minor Health 13(1): 49-60

Home Office (2001). Race Relations (Amendment) Act (2000), New Laws for a Successful Multi-Racial Britain, Proposals for Implementation. Home Office: London

Jack RH, Davies EA, Moller H (2007) Testis and prostate cancer incidence in ethnic groups in South East England. Int J Androl 30(4): 215-220

Jack RH, Davies EA, Moller H (2009) Breast cancer incidence, stage, treatment and survival in ethnic groups in South East England. Br J Cancer 100(3): $545-550$

Jacobs EA, Karavolos K, Rathouz PJ, Ferris TG, Powell LH (2005) Limited English proficiency and breast and cervical cancer screening in a multiethnic population. Am J Public Health 95(8): 1410-1416

Kagawa-Singer M, Pourat N (2000) Asian American and Pacific Islander breast and cervical carcinoma screening rates and healthy people 2000 objectives. Cancer 89(3): $696-705$

Kamangar F, Dores GM, Anderson WF (2006) Patterns of cancer incidence, mortality, and prevalence across five continents: defining priorities to reduce cancer disparities in different geographic regions of the world. J Clin Oncol 24(14): 2137-2150

Kandula NR, Wen M, Jacobs EA, Lauderdale DS (2006) Low rates of colorectal, cervical, and breast cancer screening in Asian Americans compared with non-Hispanic whites: cultural influences or access to care? Cancer 107(1): 184-192

Kernohan EE (1996) Evaluation of a pilot study for breast and cervical cancer screening with Bradford's minority ethnic women; a community development approach, 1991-93. Br J Cancer Suppl 29: S42 - S46

Lee-Lin F, Menon U, Pett M, Nail L, Lee S, Mooney K (2007) Breast cancer beliefs and mammography screening practices among Chinese American immigrants. J Obstet Gynecol Neonatal Nurs 36(3): 212-221

Li CI, Malone KE, Daling JR (2003) Differences in breast cancer stage, treatment, and survival by race and ethnicity. Arch Intern Med 163(1): 49-56

Mangtani P, Maringe C, Rachet B, Coleman MP, dos Santos Silva I (2010) Cancer mortality in ethnic South Asian migrants in England and Wales (1993-2003): patterns in the overall population and in first and subsequent generations. Br J Cancer 102(9): 1438-1443

McKinney PA, Feltbower RG, Parslow RC, Lewis IJ, Glaser AW, Kinsey SE (2003) Patterns of childhood cancer by ethnic group in Bradford, UK 1974-1997. Eur J Cancer 39(1): 92 - 97

Morris GJ, Naidu S, Topham AK, Guiles F, Xu Y, McCue P, Schwartz GF, Park PK, Rosenberg AL, Brill K, Mitchell EP (2007) Differences in breast carcinoma characteristics in newly diagnosed African-American and Caucasian patients: a single-institution compilation compared with the National Cancer Institute's Surveillance, Epidemiology, and End Results database. Cancer 110(4): $876-884$

Moser K, Patnick J, Beral V (2009) Inequalities in reported use of breast and cervical screening in Great Britain: analysis of cross sectional survey data. BMJ 338: b2025

Naish J, Brown J, Denton B (1994) Intercultural consultations: investigation of factors that deter non-English speaking women from attending their general practitioners for cervical screening. BMJ 309(6962): 1126-1128

Nanchahal K, Mangtani P, Alston M, dos Santos Silva I (2001) Development and validation of a computerized South Asian Names and Group
Recognition Algorithm (SANGRA) for use in British health-related studies. J Public Health Med 23(4): 278-285

Neal RD, Allgar VL (2005) Sociodemographic factors and delays in the diagnosis of six cancers: analysis of data from the 'National Survey of NHS patients: cancer'. Br J Cancer 92(11): 1971-1975

Netto G, lmeida Diniz F, Arshad R, Macewen M, Patel V, Syed R. Audit of Minority Ethnic Research. Scottish Executive: Edinburgh, (2001)

Power E, Miles A, von Wagner C, Robb K, Wardle J (2009) Uptake of colorectal cancer screening: system, provider and individual factors and strategies to improve participation. Future Oncol 5(9): 1371-1388

Price CL, Szczepura AK, Gumber AK, Patnick J (2010) Comparison of breast and bowel cancer screening uptake patterns in a common cohort of South Asian women in England. BMC Health Serv Res 10: 103

Renshaw C, Jack RH, Dixon S, Moller H, Davies EA (2010) Estimating attendance for breast cancer screening in ethnic groups in London. BMC Public Health 10: 157

Richards M (2011) An independent review is under way. BMJ 343: d6843

Robb K, Wardle J, Stubbings S, Ramirez A, Austoker J, Macleod U, Hiom S, Waller J (2010) Ethnic disparities in knowledge of cancer screening programmes in the UK. J Med Screen 17(3): 125-131

Sadler GR, Dhanjal SK, Shah NB, Shah RB, Ko C, Anghel M, Harshburger R (2001) Asian Indian women: knowledge, attitudes and behaviors toward breast cancer early detection. Public Health Nurs 18(5): 357-363

Sadler GR, Ko CM, Cohn JA, White M, Weldon RN, Wu P (2007) Breast cancer knowledge, attitudes, and screening behaviors among African American women: the Black cosmetologists promoting health program. BMC Public Health 7: 57

Sadler GR, Wang K, Wang M, Ko CM (2000) Chinese women: behaviors and attitudes toward breast cancer education and screening. Womens Health Issues 10(1): $20-26$

Scottish Executive. Towards a Healthier Scotland. A White Paper on Health (1999). Scottish Executive: Edinburgh

Scottish Executive Health Department. Fair for All: Working Together Towards Culturally-Competent Services (2002). Scottish Executive: Edinburgh

Smith LK, Peake MD, Botha JL (2003) Recent changes in lung cancer incidence for south Asians: a population based register study. $B M J$ 326(7380): $81-82$

Sokal R (2010) A critical review of the literature on the uptake of cervical and breast screening in British South Asian women. Qual Prim Care 18(4): $251-261$

Steele RJ, Kostourou I, McClements P, Watling C, Libby G, Weller D, Brewster DH, Black R, Carey FA, Fraser C (2010) Effect of gender, age and deprivation on key performance indicators in a FOBT-based colorectal screening programme. J Med Screen 17(2): $68-74$

Szczepura A (2005) Access to health care for ethnic minority populations. Postgrad Med J 81(953): $141-147$

Szczepura A, Price C, Gumber A (2008) Breast and bowel cancer screening uptake patterns over 15 years for UK south Asian ethnic minority populations, corrected for differences in socio-demographic characteristics. BMC Public Health 8: 346

Thomas VN, Saleem T, Abraham R (2005) Barriers to effective uptake of cancer screening among Black and minority ethnic groups. Int $J$ Palliat Nurs 11(11): 562, 564-571

Tu SP, Taplin SH, Barlow WE, Boyko EJ (1999) Breast cancer screening by Asian-American women in a managed care environment. Am J Prev Med 17(1): 55-61

Velikova G, Booth L, Johnston C, Forman D, Selby P (2004) Breast cancer outcomes in South Asian population of West Yorkshire. Br J Cancer 90(10): $1926-1932$

Watts T, Merrell J, Murphy F, Williams A (2004) Breast health information needs of women from minority ethnic groups. J Adv Nurs 47(5): 526-535

Webb R, Richardson J, Esmail A, Pickles A (2004) Uptake for cervical screening by ethnicity and place-of-birth: a population-based cross-sectional study. I Public Health (Oxf) 26(3): 293-296

Wild SH, Fischbacher CM, Brock A, Griffiths C, Bhopal R (2006) Mortality from all cancers and lung, colorectal, breast and prostate cancer by country of birth in England and Wales, 2001-2003. Br J Cancer 94(7): 1079-1085

Winter H, Cheng KK, Cummins C, Maric R, Silcocks P, Varghese C (1999) Cancer incidence in the south Asian population of England (1990-92). Br J Cancer 79(3-4): 645-654

Zaman MJ, Mangtani P (2007) Changing disease patterns in South Asians in the UK. J R Soc Med 100(6): 254-255

This work is published under the standard license to publish agreement. After 12 months the work will become freely available and the license terms will switch to a Creative Commons Attribution-NonCommercial-Share Alike 3.0 Unported License. 